one year of referrals and hence the numbers were small. ${ }^{6}$ The second study covered three years and included larger numbers of babies, but only referrals made postnatally were considered. In both studies no account was taken of confounding variables that could influence neonatal mortality.

Our study of referrals to the regional perinatal centre included hospitals from all over Northern Ireland. Cross regional referrals are not made in Northern Ireland and it proved relatively easy to trace most $(98.3 \%)$ of the obstetric and neonatal records during the three years. We also considered babies who were referred prenatally, and the only criterion for refusal was unavailability of an intensive care cot for neonates at the centre. As this was not a randomised study, we adjusted for confounding variables in comparing outcome in the groups.

Of babies initially refused admission to the centre, most $(78.6 \%)$ were subsequently accepted into other neonatal intensive care units within Northern Ireland. There was no significant difference in outcome for babies managed in these units compared with those managed in the centre. In many cases, however, there was a considerable delay before babies refused admission to the centre could be given intensive care, and their long term outcome remains uncertain. We have shown previously that the incidence of handicap is significantly higher in babies referred for intensive care after birth compared with those accepted prenatally. " A delay in starting intensive care may therefore be important. Those babies who did not receive intensive care and remained in special care baby units had a greater than threefold increase in their odds on dying. In addition, survivors from these hospitals could be expected to have a higher incidence of handicap than those sent for intensive care, although follow up studies are needed to confirm this.

There was some imbalance in the indications for prenatal referral, particularly in the number of cases of pre-eclampsia and rhesus isoimmunisation. This reflects clinical practice in that delivery of mothers with these conditions can often be delayed until an intensive care cot becomes available.

The number of babies who needed intensive care but were refused admission may be an underestimate as obstetricians and paediatricians at the hospitals that refer such babies may have known that intensive care cots were not available at the centre and therefore did not request transfer. Examination of mortality related to birth weight in individual hospitals might clarify this further.

Our study confirmed the benefits of neonatal intensive care and its particular value in improving the survival of babies of low birth weight. Short term survival seemed to be similar in smaller neonatal intensive care units and the regional perinatal centre, but we did not look at long term outcome and handicap. Further studies are needed to determine the influence of delay in starting intensive care on short term outcome and handicap. Clearly, in Northern Ireland, as in other parts of the United Kingdom, ${ }^{5}$ not enough neonatal intensive care cots are provided and the deficiency should be remedied as soon as possible.

1 Blake AM, Pollitzer MJ, Reynolds EOR. Referral of mothers and infants for intensive care. Br Med F 1979;ii:414-36.

2 Lobb MO, Morgan MEI, Bond AP, Cooke RWI. Transfer before delivery on Merseyside: an analysis of the first 140 patients. $\mathrm{Br} \mathcal{F}$ Obstet Gynaecol 1983;90:338-41.

3 Powell TG, Pharoah POD. Regional neonatal intensive care: bias and benefit. BrMed J 1987;295:690-2.

4 Cooke RW. Where should low birthweight babies be born? Br Med $\mathcal{f}$ 1986;293:974-5.

5 Royal College of Physicians of London. Medical cure of the newborn in England and Wales. London: RCP, 1988. (Report No 0-900596-79-1.)

6 Sims DG, Wynn J, Chiswick ML. Outcome for newborn babies declined admission to a regional neonatal intensive care unit. Arch Dis Child admission to

7 Roper HP. Chiswick ML, Sims DG. Referrals to a regional neonatal intensive care unit. Arch Dis Child 1988:63:403-7.

8 Cox DR. The analysis of hinary data. London: Methuen, 1970

9 Patterson CC, Halliday HL. Prediction of outcome after delivery for the very low birthweight $(\leqslant 1500 \mathrm{~g})$ infant. Paediatric and Perinatal Epidemiolog $1982: 2: 221-8$.

10 Halliday HL, Patterson CC, McClure BG, Reid MMcC. Where should low weight habies be born? Br Med f 1986;293:1437.

(Accepted 6 fuly 1989)

\title{
Survey of colourings and preservatives in drugs
}

\author{
I Pollock, E Young, M Stoneham, N Slater, J D Wilkinson, J O Warner
}

Heart and Lung Institute, Brompton Hospital,

London

I Pollock, MRCP, research registrar

J O Warner, FRCP, consultant paediatric chest physician

\section{Department of}

Dermatology, Wycombe

General Hospital,

Buckinghamshire

E Young, MRCP, senior registrar in dermatology M Stoneham MRCGP, research assistant in dermatology

N Slater, computer technician

J D Wilkinson, FRCP,

consultant dermatologist

Correspondence to:

Dr I Pollock, Department of

Child Health, St George's

Hospital, London

SW 17 0RE.

Br.Med. I 1989;299:649-51

\section{Abstract}

Objective-To assess the prevalence of colourings and preservatives in drug formulations in the United Kingdom.

Design-Postal survey.

Participants-All pharmaceutical manufacturers in the United Kingdom were requested to supply data on drug formulations with particular regard to the content of colourings and preservatives.

Main outcome measure-Prevalence in proprietary drugs of colourings or preservatives, or both, that have been implicated in adverse reactions. Computation of a list of formulations of bronchodilators, antihistamines, and antibiotics that are free of such additives.

Results-A total of 118 out of 120 pharmaceutical companies supplied the data requested. In all, 2204 drug formulations were analysed and found to contain 419 different additives, of which .52 were colourings and preservatives that have been implicated in adverse reactions; 930 formulations contained such an additive. Tartrazine was the fourth most commonly occurring colouring, being present in 124 drug formulations.

Conclusion-Many drugs contain additives that help to identify them and prolong their shelf life but are implicated in adverse reactions in some people. Some form of labelling of drug additives would enable these people to avoid drugs containing such additives.

\section{Introduction}

Many additives are used in drugs by the pharmaceutical industry for a variety of reasons, including improved identification and stability. Although adverse reactions to drugs have been reported and investigated for many years, adverse reactions to drug additives such as colourings and preservatives have been reported only over the past 30 years. ${ }^{1-4}$ Some of the colourings and preservatives that are added to drugs are also added to foods, and various adverse reactions have been attributed to them, although the validity of reports has been questioned. ${ }^{5}$ Colourings, however, have been reported to cause urticaria ${ }^{6-10}$ and preservatives, such as sulphites, to cause asthma. ${ }^{11 \cdot 13}$ There is little evidence that food or drug additives cause hyperactivity in children ${ }^{14}$ despite popular perceptions and the results of several studies. ${ }^{15-18}$

The prevalence of adverse reactions to food additives 
is uncertain, but a survey in the United Kingdom in 1987 suggested that at least $0 \cdot 01-0 \cdot 23 \%$ of the population is affected. ${ }^{14}$ To help doctors to prescribe suitable drugs for patients proved or suspected to be intolerant to colourings or preservatives, or both, we conducted a survey of drug additives with the cooperation of most drug manufacturers in the United Kingdom.

\section{Methods}

We posted a standard letter to drug manufacturers that requested details of their drug formulations with special regard to the content of colourings and preservatives. The information was entered into a database, and the data were analysed with regard to the additives most commonly reported to cause adverse reactions. The box lists the additives included in this definition; the colourings were mostly those previously derived from coal tar (for example, tartrazine), and the preservatives included antioxidants (for example, benzoates, sulphites, butylated hydroxyanisole, and butylated hydroxytoluene). If evidence to implicate an additive in an adverse reaction was inconclusive for the purposes of the survey we considered that it could cause such a reaction.

\section{Results}

A total of 120 pharmaceutical manufacturers were contacted during 1988, and only two would not supply the information requested. The manufacturers gave us permission to publish information on drug additives in named drugs in the categories of the British National Formulary (see table II). In all, the drugs contained 419 different additives. Of these, 52 colourings and preservatives were categorised as having been implicated in adverse reactions, leaving 367 for which no evidence of adverse effects existed.

Table I gives the prevalence in $930 \mathrm{drug}$ formulations of some of the colourings and preservatives that have been implicated in adverse reactions. Erythrosine was the commonest colouring, being added to 191 drugs; tartrazine was added to 124 , and benzoates occurred in 290. Table II gives the additives in drugs according to the categories of the British National Formulary. Central nervous system agents were the drugs that most commonly contained a colouring or preservative, or both, that had been implicated in adverse reactions.

Of the 2204 drug formulations analysed, 532 contained a colouring, 281 a preservative, and 117 both a colouring and a preservative that had been implicated in adverse reactions. Table III lists formulations of bronchodilators, antihistamines, and antibiotics that are free of such colourings and preservatives. Data

TABLE II - Number of drug formulations ( $n=930$ ) with colourings or preservatives, or both, that have been implicated in adverse reactions according to categories in British National Formulary

\begin{tabular}{lccc}
\hline \multicolumn{1}{c}{ Category of drug } & $\begin{array}{c}\text { With } \\
\text { preservative } \\
\text { implicated in } \\
\text { adverse reactions }\end{array}$ & $\begin{array}{c}\text { With colouring } \\
\text { implicated } \\
\text { in adverse } \\
\text { reactions }\end{array}$ & $\begin{array}{c}\text { With colourings } \\
\text { and preservatives } \\
\text { implicated in } \\
\text { adverse reactions }\end{array}$ \\
\hline Gastrointestinal & 32 & 32 & 11 \\
Cardiovascular & 13 & 110 & 5 \\
Respiratory & 43 & 40 & 27 \\
Neurological & 33 & 141 & 28 \\
Infections & 35 & 58 & 3 \\
Endocrine & 10 & 11 & 10 \\
Obstetrics, gynaecology, and urinary tract & 2 & 4 & 4 \\
Malignancy & 7 & 8 & 1 \\
Nutrition and blood & 25 & 58 & \\
Musculoskeletal and joint & 6 & 41 & 117 \\
Eyc & 3 & 10 & \\
Ear, nose, and throat & 7 & 16 & \\
Skin & 46 & 1 & \\
Immunological & 19 & 532 & \\
Anaesthesia & 281 & & \\
\hline Total & & & \\
\hline
\end{tabular}

\section{Drug additives that have been reported to} cause adverse reactions

$\begin{array}{ll} & \text { Colourings } \\ \text { Amaranth } & \text { Erythrosine BS } \\ \text { Black PN } & \text { Green S } \\ \text { Blue (colour index Nos } & \text { Indigo Carmine } \\ \left.12196 \text { and } 16383^{\star}\right) & \text { Patent blue V } \\ \text { Brilliant blue FCF } & \text { Ponceau 4R } \\ \text { Brown FK } & \text { Quinoline yellow } \\ \text { Brown HT } & \text { Red 2G } \\ \text { Brown (colour index No } & \text { Sunset yellow FCF } \\ 18285)^{\star} & \text { Tartrazine } \\ \text { Buff }(\text { colour index No } & \text { Yellow 2G } \\ 17175)^{\star} & \text { Various commercial mixes } \\ \text { Carmoisine } & \text { containing the above } \\ \text { Disperse blues } & \text { colourings } \\ \text { Disperse pinks } & \\ & \\ \text { Benzoates } & \text { Preservatives and antioxidants } \\ \text { Sulphites } & \text { Butylated hydroxyanisole } \\ \star \text { Not permitted food additives. } & \text { Butylated hydroxytoluene }\end{array}$

were not obtained on the amount of a particular additive in each drug; available data, however, suggest that some tablets contain up to $2 \cdot 7 \mathrm{mg}$ of tartrazine. ${ }^{20}$

\section{Discussion}

Many drug additives have important functions. Bright and stable colouring of drugs is important because patients who take a variety of drugs need to be able to identify them to minimise the risk of accidental overdose and to help identification of drugs in people who have deliberately taken an overdose. Often the most stable and strong colourings are those implicated in adverse reactions, and many of these wëre previously derived from coal tar. ${ }^{21}$ Some colourings that occur naturally are available commercially, but generally, with the exception of iron and titanium oxides, they are less powerful colourants. Also, some of the colourings used to replace those implicated in adverse reactions may not be completely inert.

Clearly, drugs need to have a reasonable shelf life, and therefore many drugs, especially liquid formulations, contain benzoates and to a lesser extent sulphites. Sulphites can cause bronchospasm in some people with asthma (probably by liberating sulphur dioxide), and once the presence of sulphite in a drug formulation has been identified such people can avoid the formulation.

Several drug manufacturers informed us that tartrazine and some other related colourings have been replaced over the past five years; our survey, however, shows that they are still in widespread use. Comparisons with drug formulations in Europe are limited to data from a recent survey in Switzerland, from which it seems that the number of drugs containing azo dyes in that country is similar to that in the United Kingdom; tartrazine is the fourth commonest azo dye in both countries."2 The data from the present survey are as accurate as possible, but drug formulations are subject to change from time to time, and specific information should be requested from the manufacturer. We did not study generic drug formulations, although they probably contain additives implicated in adverse reactions.

The mechanism of intolerance to colourings and preservatives is unknown. There is little evidence to support an immunological mechanism, but some recent studies support a pharmacological mechanism. ${ }^{23-25}$ As no tests of intolerance to additives performed in vitro have been validated such intolerance must be diagnosed clinically and only when symptoms improve when additives are avoided; ideally, blind 


\begin{tabular}{|c|c|c|c|c|c|}
\hline Proprietary (approved) name of drug & Formulation & Manufacturer & Proprietary (approved) name of drug & Formulation & Manufacturer \\
\hline \multicolumn{3}{|c|}{ Bronchodilators } & Calthor (ciclacillin) & Tablets & Ayerst \\
\hline Alupent (orciprenaline) & Tablets & Boehringer Ingelheim & Ceporex (cephalexin) & Capsules & Glaxo \\
\hline Bricanyl, Bricanyl SA, and Bricanyl compound & & & Ciproxin (ciprofloxacin) & Tablets & Baypharm \\
\hline (terbutaline) & Tablets & Astra & Colomycin (colistin) & Tablets & Pharmax \\
\hline Bronchodil (reproterol) & Tablets & Degussa & Eradacin (acrosoxacin) & Capsules & Sterling Research \\
\hline CD Franol and CD Franol Plus (ephedrine, & & & Fasigyn (tinidazole) & Tablets & Pfizer \\
\hline theophylline, and phenobarbitone) & Tablets & Sterling-Winthrop & Fucidin (sodium fusidate) & Tablets & May and Baker \\
\hline Nuelin and Nuelin SA (theophylline) & Tablets & Riker & Furadantin (nitrofurantoin) & Tablets & Norwich Eaton \\
\hline Phyllocontın Contınus (aminophylline) & $\begin{array}{l}\text { Tablets - normal } \\
\text { strength, forte, }\end{array}$ & & Hiprex (hexamine) & Tablets & Riker \\
\hline & and paediatric & Napp & Ipral (trimethoprim) & Tablets & Squibb \\
\hline Sabidal SR 270 (choline theophyllinate) & Tablets & Zyma & Kelfizine W (sulfametopyrazine) & Tablets & Farmitalia Carlo Erba \\
\hline Slo-phylline (theophylline $(60$ and $125 \mathrm{mg}$ ) & Capsules & Lipha & Ladropen (flucloxacillin) & Capsules & Berk \\
\hline Tedral (theophylline and ephedrine) & Tablets & Parke-Davis & Laratrim (co-trimoxazole) & Tablets & Lagap \\
\hline Theodrox (aminophylline) & Tablets & Riker & Ledermycin (demeclocycline $300 \mathrm{mg}$ ) & Capsules & Lederle \\
\hline Uniphylline Continus (theophylline) & Tablets & Napp & Metrolyl (metronidazole) & Tablets & Lagap \\
\hline Volmax (salbutamol) & Tablets & Duncan Flockhart & $\begin{array}{l}\text { Mictral (nalidixic acid) } \\
\text { Minocin (minocycline) ( } 50 \mathrm{mg} \text { ) }\end{array}$ & $\begin{array}{l}\text { Granules } \\
\text { Tablets }\end{array}$ & $\begin{array}{l}\text { Sterling-Winthrop } \\
\text { Lederle }\end{array}$ \\
\hline \multicolumn{3}{|c|}{ Antihistamines } & Miraxid (pivampicillin) & $\begin{array}{l}\text { Tablets and } \\
\text { paediatric }\end{array}$ & \\
\hline Actidil (triprolidine) & Tablets & Wellcome & \multirow{3}{*}{ Monotrim (trimethoprim) } & suspension & Fisons \\
\hline Alunex (chlorpheniramine) & Tablets & Steinhard & & Tablets and & \\
\hline Dimotane and Dimotane LA & & & & suspension & Duphar \\
\hline (brompheniramine) & Tablets & A H Robins & Myambutol (ethambutol) $(40$ & Tablets & Lederle \\
\hline Fenostil Retard (dimethindene) & Tablets & Zyma & Mynah 200 (ethambutol and isoniazid) & Tablets & Lederle \\
\hline Hismanal (astemizole) & Tablets and & & Negram (nalidixic acid) & Tablets & Sterling Research \\
\hline & suspension & Janssen & Nidazol (metronidazole) & Tablets & Steinhard \\
\hline $\begin{array}{l}\text { Lergoban (diphenylpyraline) } \\
\text { Optimine (azatadine) }\end{array}$ & Tablets & $\begin{array}{l}\text { Riker } \\
\text { Kirby-Warrick }\end{array}$ & Pondocillin (pivampicillin) & Tablets and & 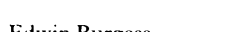 \\
\hline Periactin (cyproheptadine) & Tablets & Merck Sharp and Dohme & Rifater (isoniazid, pyrazinamide, and & sachet & Edwin Burgess \\
\hline Piriton (chlorpheniramine) & Tablets & Allen and Hanbury & rifampicin) & Tablets & Merrel Dow \\
\hline Primalan (mequitazine) & Tablets & May and Baker & Rimactane (rifampicin) (150 and $300 \mathrm{mg})$ & Capsules & Ciba-Geigy \\
\hline Semprex (acrivastine) & Capsules & Wellcome & Rimactazid 150 (rifampicin and isoniazid) & Tablets & Ciba-Geigy \\
\hline Tavegil (clemastine) & Tablets & Sandoz & Selexid (pivmecillinam) & Tablets and & \\
\hline Thephorin (phenindamine) & Tablets & Sinclair & & suspension & Leo \\
\hline $\begin{array}{l}\text { Tinset (oxatomide) } \\
\text { Triludan (terfenadine) }\end{array}$ & $\begin{array}{l}\text { Tablets } \\
\text { Tablets }\end{array}$ & $\begin{array}{l}\text { Janssen } \\
\text { Merrell Dow }\end{array}$ & Septrin (co-trimoxazole) & $\begin{array}{l}\text { Tablets-normal } \\
\text { strength and }\end{array}$ & \\
\hline Zirtek (cetririzine) & Tablets & Allen and Hanbury & & forte & Wellcome \\
\hline & & & Stafoxil (flucloxacillin) & Capsules & Brocades \\
\hline Antibi & otics & & Syraprim (trimethoprim) & Tablets & Wellcome \\
\hline Ambaxin (bacampicillin) & Tablets & Upjohn & Tetralysal 300 (lymecycline) & Tablets & Farmitalia Carlo Erba \\
\hline Amoxil (amoxycillin) & Tablets & Bencard & Trimogal (trimethoprim) & Tablets & Lagap \\
\hline Ampilar (ampicillin) & Syrup & Lagap & Trimopan (trimethoprim) & Tablets & Berk \\
\hline Augmentin (amoxycillin and clavulanate) & Dispersible & & Uticillin (carfecillin) & Tablets & Beecham \\
\hline & tablets and & & Velosef (cephradine) & Syrup & Squibb \\
\hline & suspension & Beecham & Vibramycin (doxycycline) & Capsules & Pfizer \\
\hline Bacrim (co-trimoxazole) & Tablets & Roche & Zadstat (metronidazole) & Tablets & Lederle \\
\hline Baxan (cefadroxil) & Capsules & Bristol-Myers & Zinamide (pyrazinamide) & Tablets & Merck Sharp and Dohme \\
\hline
\end{tabular}

placebo controlled challenges should also be performed. ${ }^{26}$

In 1986 compulsory labelling of foods containing additives was introduced in the United Kingdom, and as a consequence the range and number of foods available without such additives has increased. Whether the prevalence of reactions to food additives has declined since then would be difficult to determine. Compulsory labelling of drugs containing additives exists in some countries and is under consideration in the United Kingdom. It would clearly be useful for doctors to be able to refer to the Association of the British Pharmaceutical Industry's data sheet compendium for guidance when they are prescribing drugs for patients who have been proved or are suspected to be intolerant to colourings or preservatives, or both. Drug manufacturers are usually helpful in supplying information about the additives in their products, but for busy clinicians obtaining information this way can be time consuming.

At present patients presenting with symptoms, such as urticaria, that could be provoked by colourings or preservatives, or both, should avoid additives in drugs and food. When the additive content of a drug is unknown they should take a white tablet formulation as these are commonly free of colourings and preservatives and usually can be crushed and added to food for administration to children.

IP, EY, and NS were supported as part of a grant from the Ministry of Agriculture, Fisheries, and Food.

\footnotetext{
1 Lockev SD. Allergic reactions to F D and C vellow No 5 tartrazine, an aniline dve used as a coloring and identifying agent in various steroids. Ann Allergy 1959;17:71.

2 Jenkins P, Michelson R, Emerson PA. Adverse drug reaction to sunset yellow in rifampicin/isoniazid tablet. Lancet 1982;ii:385.

3 Nagel JE, Fuscaldo JT, Fireman P. Paraben allergy. FAMA 1977;237:1594.
}

4 Reisman RE. Delayed hypersensitivity to methiolate preservative. Fournal of Allergy 1969;43:245.

5 Simon RA. Adverse reactions to drug additives. F Allergy Clin Immunol 1984;74:623-30.

6 Michaelsson G, Juhlin L. Urticaria induced by preservatives and dye additives in food and drugs. Br f Dermatol 1973:88:525-32.

7 Supramanium $\mathrm{G}$, Warner JO. Artificial food additive intolerance in patients with angio-oedema and urticaria. Lancet 1986;ii:907-9.

8 Settipane GA, Chafee FH, Postman M, Levine MI. Significance of tartrazine sensitivity in chronic urticaria of unknown etiology. F Allergy Clin Immunol $1976 ; 57: 541-6$

9 Ros A, Juhlin L, Michaelsson G. A follow-up study of patients with recurrent urticaria and hypersensitivity to aspirin, benzoates and azo dyes. $\operatorname{Br} \mathcal{I}$ Dermatol 1976;95:19-24.

10 Warin RP, Smith RJ. Role of tartrazine in chronic urticaria. $\mathrm{Br} \mathrm{Med} \mathcal{f}$ 1982;284: 1443-4

11 Stevenson DD, Simon RA. Sensitivity to ingested metabisulphites in asthmatic subjects. F Allergy Clin Immunol 1981;68:26-32.

12 Weber RW, Hoffman M, Raine Jr DA, Nelson HS. Incidence of bronchoconstriction due to aspirin, azo dyes, non-azo dyes, and preservatives in a population of perinial asthmatics. F Allergv Clin Immunol 1979;64:32-7.

13 Beasley R, Rafferty P, Holgate ST. Adverse reactions to the non-drug constituents of nebuliser solutions. Br 7 Clin Pharmacol 1988:25:283-7.

14 Taylor EA. The overactive child. Oxford: Blackwell, 1986.

15 Feingold BF. Why your child is hyperactive. New York: Random House, 1975. 6 Egger J, Carter CM, Graham PJ, Gumley D, Soothill JF. Controlled trial of oligoantigenic treatment in the hyperkinetic syndrome. Lancet $1985 ; 1: 540-5$. 17 David TJ. Reactions to dietary tartrazine. Arch Dis Child 1987;62:119-22.

18 Pollock I, Warner JO. The effect of artificial food colours on childhood behaviour. Arch Dis Child (in press).

19 Young E, Patel S, Stoneham M, Rona R, Wilkinson JD. The prevalence of reaction to food additives in a survey population. $f R$ Coll Physicians L ond 1987;21:241-7.

20 Smith LJ, Slavin RG. Drugs containing tartrazine dye. $f$ Allergy Clin Immunol 1976;58:456-70.

21 Hess H, Schrank J. Colouration of pharmaceuticals-possibilities and technical problems. Acta Pharm Tech 1979;25(suppl 8):77-87.

22 Kolly M, Pecoud A, Frei PC. Additives contained in drug formulations most frequently prescribed in Switzerland. Ann Allercy 1988;62:21-5.

23 Murdoch RD, Lessof MH, Pollock I, Young E. Effects of food additives on leukocyte histamine release in normal and urticarial subjects. $尹 R$ Coll Physiciuns Lond 1987;21:251-6.

24 Murdoch RD, Pollock I, Naeem S. Tartrazine induced histamine release in vivo in normal subjects. $f R$ Coll Physicians Lond 1987;21:257-61.

25 Murdoch RD, Pollock I, Young E, Lessof $M H$. Food additive-induced urticaria: studies of mediator release during provocation testing. $f R$ Coll Physicians L.ond 1987;21:262-6.

26 Warner JO. Artificial food additive intolerance: fact or fiction? In: Dobbing J, d. Food intolerance. London: Baillière and Tindall, 1987:133-47.

Accepted 11 fulv 1989 